\title{
Effects of biodiversity and plant community composition on productivity in semiarid grasslands of Hulunbeir, Inner Mongolia, China
}

\author{
Xiao-Xuan Zheng, ${ }^{1,2}$ Guo-Hua Liu, ${ }^{1}$ Bo-Jie Fu, ${ }^{1}$ Tian-Tian Jin, ${ }^{1,2}$ and Zhan-Feng Liu ${ }^{3}$ \\ ${ }^{1}$ State Key Laboratory of Urban and Regional Ecology, Research Center for Eco-Environmental Sciences, Chinese Academy \\ of Sciences, Beijing, China. ${ }^{2}$ Graduate University of Chinese Academy of Sciences, Beijing, China. ${ }^{3}$ Institute of Ecology, \\ South China Botanical Garden, Chinese Academy of Sciences, Guangzhou, China \\ Address for correspondence: Guo-Hua Liu, P.O. Box 2871, Beijing 100085, China. Voice: +86-10-62849803; fax: \\ +86-10-62923557. ghliu@rcees.ac.cn
}

\begin{abstract}
Many recent studies have focused on the relationship between biodiversity and ecosystem functioning, such as investigations into the productivity of experimental plant communities. One of the central issues affecting the functioning of ecosystems is the diversity of resident species richness and the composition of the plant community. However, one challenge to experimental studies is that results from artificial ecosystems may have little value for predicting loss of diversity and function degradation in natural ecosystems. Thus, recent studies have focused more on investigations of natural ecosystems; these studies have found that species diversity and ecosystem productivity usually correlate with various abiotic factors including environmental effects, such as soil nutrition and precipitation, as well as anthropic activities, such as grazing and agricultural yield. In this study, we aimed to test the validity of biotic factors reported in experimental studies to be major factors affecting the productivity of ecosystems, and then to determine whether the relationship between biodiversity and ecosystem function is confounded by environmental factors. We investigated the effects of plant biodiversity and community composition on ecosystem function (productivity) in semiarid grassland in Inner Mongolia, China that contained three vegetation types: arid steppe, steppe, and meadow steppe. Our results show that both diversity and community composition significantly affect productivity and are better predictors of productivity than environmental factors, such as soil conditions. Our findings are consistent with the assumptions of niche complementarity. This study suggests that both biodiversity and community composition are important biotic factors in the functioning of ecosystems located in semiarid grasslands. In addition, environmental parameters, such as soil conditions influence productivity indirectly by affecting both biotic factors at the same time.
\end{abstract}

Keywords: productivity; biodiversity; plant community composition; semiarid grasslands

\section{Introduction}

The relationship between biodiversity and ecosystem functions, such as productivity has been a central issue in the field of ecological sciences for the past several decades (Grime 1997; Huston 1997; Waide et al. 1999; Loreau 2000; Loreau et al. 2001; Thompson et al.2005). However, most of these studies have been conducted in artificial experimental fields and have examined different diversity levels created by randomly selecting plant species from a species pool. Both linear and nonlinear relationships were found between biodiversity and productivity of ecosystem (Naeem et al. 1994; Tilman 1996; Tilman et al. 1997a; Hector et al. 1999; Zhang and Zhang 2006). As to the underlying mechanism, some ecologists maintain that niche complementarity can explain the asymptotic increase in productivity with increasing species diversity. An increase in species diversity leads to mixtures of species that can utilize available resources efficiently, therefore increasing ecosystem productivity or stability (Tilman 1996; Loreau 1998; Li and Charnov 2001; Loreau and Hector 2001). This concept is known as "niche 
complementarity." Despite evidence in its favor, several authors have questioned the validity of this concept and instead point to the sampling effect: more plant species increase the probability of productive species and thus cause higher productivity of ecosystem (Grime 1997; Huston 1997; Huston et al. 2000). Some authors have found that niche complementarity and sampling effect are not mutually exclusive absolutely contrary. Interestingly, they found that a sampling effect appears usually at the initial stage of the experiment and is gradually replaced by niche complementarity in the longer term (Tilman et al. 2001). These results have been verified in experiments in an aquatic ecosystem (Zhang and Zhang 2006).

To understand the underlying mechanism of the relationship between biodiversity and ecosystem functioning, it is important to identify clearly the dominant factors affecting this relationship. Early studies measured ecosystem productivity only in terms of the number of species. Higher productivity corresponded to more species being selected randomly in artificial experiments. Later research, however, found that not only species number but also the composition of the plant community strongly influenced the ecosystem. In fact, several ecologists maintain that community composition is the key biotic factor affecting ecosystem functioning (Hooper and Vitousek 1997; Tilman et al. 1997a; Petchey and Gaston 2002). Thus recent studies have used species number and plant community composition, measured by functional group composition, as two different measures of ecosystem functioning, both of which are affected by species diversity (Tilman et al. 1997a; Naeem and Wright 2003; Reich et al. 2004). Both species diversity and community composition influence productivity to approximately the same extent, since the effect of diversity on productivity is proportional to the differences in how efficiently different species use available resources (Tilman et al. 1997b). The most common method used to classify plant functional groups is to cluster species with shared taxonomic, physiological, and morphological traits into functional groups, with the assumption that groups with similar traits differ in their response and effect on resources such as nitrogen (Lavorel and Garnier 2002; Petchey and Gaston 2002). However, some authors have questioned this conventional classification of functional groups, suggesting that this method underestimates the effect of functional diversity on ecosystem functioning (Wright et al. 2006). This controversy indicates the need for a widely acceptable method for comprehensively evaluating plant community composition.

Previous experimental studies are limited in that they eliminate or control factors, such as environmental variation, soil nutrition heterogeneity, and anthropic disturbance at a similar level. The applicability of the findings of empirical research to natural ecosystems has been questioned, given that the biodiversity of natural ecosystems will be less important for ecosystem functioning than environmental and anthropogenic factors (Grime 1997; Cardinale et al. 2000; Huston and McBride 2002; Kahmen et al. 2005a). In addition, some have argued that the results achieved in experimental studies may have little value for species loss in those natural ecosystems in which species extinction is not random but directed (Diaz and Cabido 2001). Chapin and Loreau have therefore suggested that the study of biodiversity and ecosystem functioning should seek to replicate more closely the parameters of natural ecosystems in order to determine how and why abiotic factors influence their productivity (Chapin et al. 2000; Loreau et al. 2001).

In natural ecosystems, several theories predict that diversity peaks at intermediate levels of productivity and decreases at high or low productivity (Waide et al. 1999; Mittelbach et al. 2001). Although productivity is considered to be the major parameter determining the relationship between biodiversity and ecosystem functioning, it is demonstrated that this procedure is also affected by the covariation of other abiotic factors. This illustrates the complex effects of environment, such as climatic changes on species diversity in natural ecosystems (Gough et al. 1994; Chen et al. 2003; Kahmen et al. 2005). It also indicates the importance of controlling environmental factors effectively in order to test the effect of biodiversity on productivity in complex natural communities. The huge number of variables affecting biodiversity makes this operation very difficult. In order to test the direct and indirect effects of diversity and environmental variables on ecosystem functioning, multivariate models that control environmental variables statistically are necessary, such as the model used in this study.

The presence of one or a few dominant species strongly affects productivity and therefore the 


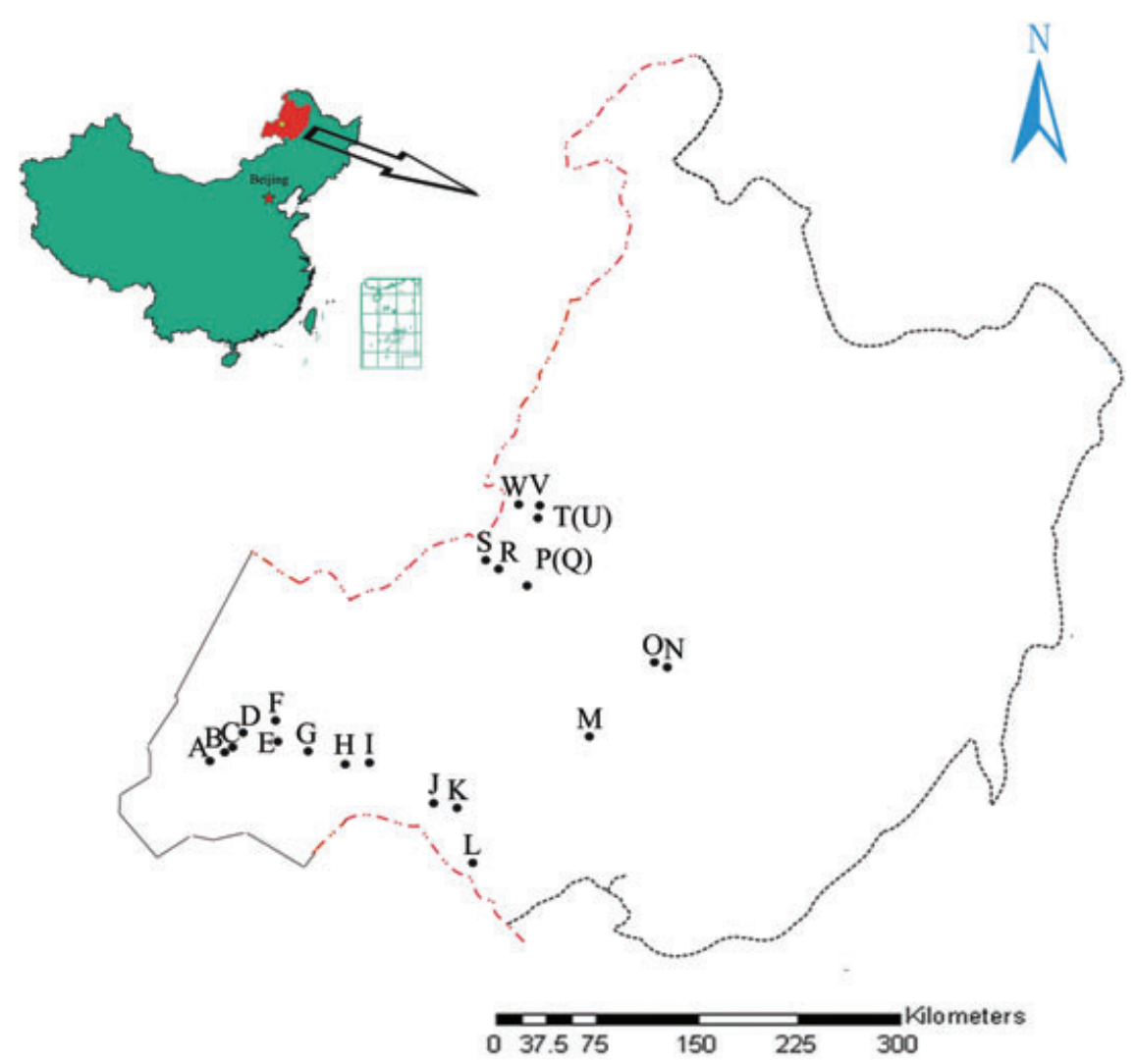

Figure 1. Sampling sites in Hulunbeir grassland.

relationship between biodiversity and productivity (Spehn et al. 2002). On the other hand, some rare species may also have important impacts on ecosystem functioning (Lyons et al. 2005). For this reason, as we did in this study, studies of the relationship between species diversity and the functioning of natural ecosystems should involve examining the effects of specific species and overall plant community composition.

In this study, we sought to determine (1) the effect of plant diversity and community composition on productivity in a semiarid natural grassland; (2) the effect of the direct and indirect interactions of environmental variables (e.g., soil nutrition) on diversity, community composition, and productivity; and (3) whether the community composition is affected more by particular dominant species or by a combination of both dominant and rare species.

\section{Materials and methods}

\section{Study area and study sites}

The study area is located in the western part of the Daxing'anling Mountains, Hulunbeir $\left(115^{\circ} 31^{\prime} \sim 126^{\circ} 04^{\prime} \mathrm{E}, 47^{\circ} 05^{\prime} \sim 53^{\circ} 20^{\prime} \mathrm{N}\right)$, Inner Mongolia, China (Fig. 1). Mean annual precipitation (MAP) is $339 \mathrm{~mm}$ and temperature (MAT) is $-2.2^{\circ} \mathrm{C}$. The orographic characteristics were similar across the area; the maximal variation in height is less than $50 \mathrm{~m}$. Hulunbeir grassland is seminatural grassland that is one of the best-protected steppes in China. Grazing activities are strictly controlled in terms of the number of livestock and grazing region. In addition, more than 130 plant species inhabit this area. The composition and structure of the plant community change with climatic and edaphic gradients, making this area suitable for research on the effects of biodiversity and plant community 
composition on the functioning of natural ecosystems in which environmental factors must also be considered. Floristically distinct plant communities in this region include western arid steppe, central semiarid steppe, and eastern meadow steppe (Inner Mongolia Federal Investigation Team of CAS 1985). Edaphic characteristics (physical traits and chemical nutrition) are heterogeneous and the main soil types are chernozem and chestnut.

A total of 23 grasslands were studied in August of 2005, June and July of 2006, and June-August of 2007. Sites were settled along latitudinal and longitudinal gradients. To qualify for the study, all sites had to be in locations with similar topography and solar conditions. Anthropic disturbances were not a factor, since all sites were selected in regions without grazing activities. In each site, five $1 \times 1 \mathrm{~m}$ plots were established at a distance of $10 \mathrm{~m}$ from one another. All plant species in the $1 \times 1 \mathrm{~m}$ plots were identified and the percent cover data for each plot were evaluated. Species abundance height, percent cover, and biomass of each plant species in the plot were recorded. Three random samples were picked and tested in each of the five plots. Soil moisture, bulk density, and soil-available nutrients were determined for each sample.

\section{Sampling of soil, vegetation data, and productivity}

In 2006 and 2007, five cores $(5 \times 20 \mathrm{~cm})$ were taken from each randomly selected plot. Soil from the five samples from a given plot was mixed and sieved to $2 \mathrm{~mm}$. The soil properties were analyzed using the methods of $\mathrm{Lu}$ ( $\mathrm{Lu} \mathrm{1999)}$. Soil moisture content (SMC) at each site was determined gravimetrically by weighing samples, drying them in an oven at $105^{\circ} \mathrm{C}$ for $12 \mathrm{~h}$, and reweighing. Bulk density (BD) of the soils was determined from an undisturbed soil sample using the core method. Soil organic carbon (SOC) was determined by the $\mathrm{K}_{2} \mathrm{Cr}_{2} \mathrm{O}_{7}$ titration method after digestion. Total phosphorus (TP) was determined colorimetrically following wet digestion with $\mathrm{H}_{2} \mathrm{SO}_{4}$ plus $\mathrm{HClO}_{4}$. Available phosphorus (AP) was extracted using a $0.5 \mathrm{~mol} \cdot \mathrm{L}^{-1} \mathrm{NaHCO}_{3}$ solution $(\mathrm{pH}$ 8.5), and then determined by colorimetry. Total nitrogen (TN) was determined by the Kjeldahl procedure, followed by titration analysis. Available nitrogen (AN) was determined by the titration method following pervasion.
We used aboveground biomass as a surrogate for productivity in this study. In each $1 \times 1 \mathrm{~m}$ plot, biomass was harvested at peak standing biomass $2 \mathrm{~cm}$ above ground level after vegetation data had been obtained. The plant material was dried at $80^{\circ} \mathrm{C}$ to constant weight and then weighed.

\section{Statistical analysis}

First, to estimate the compositional differences among plant communities of 23 grasslands, we applied nonmetric multidimensional scaling (NMDS) ordination techniques using the program PC-ORD. NMDS is an iterative search for ranking and placement of $\mathrm{n}$ entities (samples) in $\mathrm{k}$ dimensions (ordination axes) in a way that minimizes the stress of the k-dimensional configuration. The "stress" value is a measure of departure from monotonicity in the relationship between the dissimilarity (distance) in the original p-dimensional space and in the reduced k-dimensional ordination space (Clarke 1993). As a distance measure, the Bray-Curtis coefficient was used; this is one of the most efficient measures for this purpose (Faith et al. 1987). In order to represent the composition of plant communities accurately, we input the data of relative importance value for species in NMDS. The value for relative importance was calculated from the relative height (defined as species height/total height in the plot), relative species richness (species abundance/total abundance), and relative biomass (species biomass/total biomass) according to the following formula: Relative importance $=($ relative abundance + relative height + relative biomass) $/ 3$. In addition, to analyze which species correlate with variations in species composition and diversity within the plant communities investigated, we performed linear regression analysis for relative species importance according to the NDMS axes.

Second, we calculated plant species richness and diversity (Shannon-Wiener, evenness, and Simpson's index). Then we used the principal component analysis (PCA) to operationalize the edaphic characteristics. This procedure extracted the information as four axes of a standardized PCA. Since PCA axes are by definition orthogonal and independent of each other, so this procedure creates composite independent variables and avoids spurious correlations. The PCA axes explained most 
of the variance and introduced new PCA-derived variables. These PCA-derived variables were used in all subsequent analyses as independent parameters. Because the extracted axes explained most of the total variance in the original parameters, very little information was lost in this procedure. To avoid distortions, soil nutrition variables were square-root transformed before analysis. Thereafter, we used linear regressions to analyze how plant diversity and community composition, as measured by species richness, Shannon-Weiner, evenness, Simpson' Index, and NMDS axes, affect productivity. In the final step, we used multiple stepwise regressions to test whether the PCA-derived variables were significant predictors for parameters that correlated significantly with productivity. Otherwise, we tested that how well PCA-derived variables predicted productivity. All regression analyses were performed using SPSS (version 10).

\section{Results}

\section{Plant diversity and soil characteristics}

Plant species richness in the 23 grasslands investigated ranged from 6 to 39 species per meter square. The Shannon-Wiener value varied between 1.71 and 3.03, evenness ranged from 0.42 to 0.92 , and the minimum and maximum values of Simpson's index were $0.72-0.93$. Aboveground biomass varied from 21.9 to $173.63 \mathrm{~g} \cdot \mathrm{m}^{-2}$, and the mean value was $74.26 \mathrm{~g} \cdot \mathrm{m}^{-2}$ (Table 1 ).

Some physical and chemical properties, such as soil moisture content, $\mathrm{BD}, \mathrm{SOC}, \mathrm{TP}, \mathrm{AP}, \mathrm{TN}, \mathrm{AN}$, $\mathrm{C} / \mathrm{N}, \mathrm{C} / \mathrm{P}$, and N/P were also analyzed. The results are listed in Table 1.

\section{Plant community composition}

NMDS showed that a two-dimensional solution was sufficient to explain plant community composition. The stress value was 21.5. The result indicated that plant community composition varied significantly between different plots (Fig. 2). On the basis of these data, all 23 sites could be assigned into three groups that matched the three kinds of plant vegetation in Hulunbeir grassland: arid steppe, steppe, and meadow steppe. For further analysis, we used the scores of the first two axes (NMDS1 and NMDS2) as proxies for plant community composition. According to the regression, several plant species have significant positive or negative relationships with the NMDS axes of plant diversity and productivity (Table 2).

\section{Extraction of edaphic data}

PCA showed that four axes were aggregated to delineate soil nutrition variables. These four axes explained $91.25 \%$ of the variance of all edaphic parameters, and they were labeled as soill, soil2,

Table 1. Descriptive statistics of productivity, plant diversity, and soil nutrition variables

\begin{tabular}{|c|c|c|c|c|}
\hline Variables & Min & Max & Mean & SD \\
\hline Aboveground biomass $\left(\mathrm{g} \cdot \mathrm{m}^{-2}\right)$ & 21.90 & 173.63 & 74.26 & 38.95 \\
\hline Shannon-Wiener & 1.71 & 3.03 & 2.37 & 0.35 \\
\hline Evenness & 0.74 & 0.92 & 0.85 & 0.04 \\
\hline Simpson's diversity & 0.72 & 0.93 & 0.86 & 0.05 \\
\hline Richness & 6.00 & 39.00 & 17.19 & 5.98 \\
\hline $\mathrm{SOC}\left(\mathrm{g} \cdot \mathrm{kg}^{-1}\right)$ & 0.33 & 41.23 & 22.16 & 10.24 \\
\hline $\mathrm{TP}\left(\mathrm{g} \cdot \mathrm{kg}^{-1}\right)$ & 0.11 & 0.92 & 0.43 & 0.16 \\
\hline $\mathrm{AP}\left(\mathrm{mg} \cdot \mathrm{kg}^{-1}\right)$ & 4.28 & 18.72 & 7.84 & 2.41 \\
\hline $\mathrm{TN}\left(\mathrm{g} \cdot \mathrm{kg}^{-1}\right)$ & 0.58 & 3.26 & 2.08 & 0.75 \\
\hline $\mathrm{AN}\left(\mathrm{mg} \cdot \mathrm{kg}^{-1}\right)$ & 29.96 & 338.12 & 128.16 & 65.82 \\
\hline $\mathrm{C} / \mathrm{N}$ & 0.41 & 16.41 & 10.23 & 2.68 \\
\hline $\mathrm{C} / \mathrm{P}$ & 1.24 & 105.69 & 53.07 & 23.22 \\
\hline $\mathrm{N} / \mathrm{P}$ & 1.97 & 8.24 & 5.02 & 1.54 \\
\hline Soil moisture content (SMC) (\%) & 1.79 & 17.68 & 8.24 & 4.44 \\
\hline Bulk density $\left(\mathrm{g} \cdot \mathrm{cm}^{-3}\right)$ & 0.99 & 1.67 & 1.31 & 0.18 \\
\hline
\end{tabular}




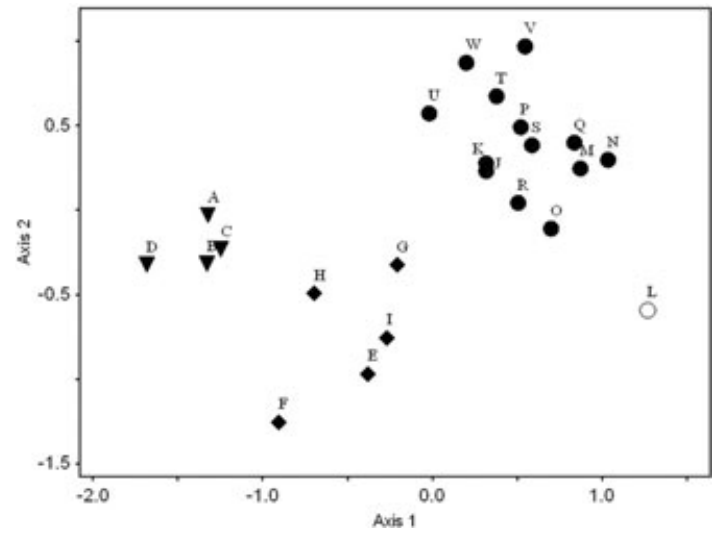

Figure 2. Nonmetric multidimensional scaling (NMDS) ordination of the 23 grassland sites. Triangles, arid steppe grassland sites; diamonds, steppe grassland sites; filled circles, meadow steppe grassland sites; empty circles, sand grassland at the margin of forests.

soil3, and soil4. Table 3 shows the PCA results. Soil1 was mainly related to SOC, TN, C/P, SWC, and BD. Soil2 was related to TP and N/P. Soil3 was mainly correlated with $\mathrm{AN}$ and $\mathrm{C} / \mathrm{N}$. Soil4 correlated with AP (Table 3).

\section{The relationship between plant diversity/community composition, and productivity}

The plant species richness and Shannon-Wiener value had significant effects on productivity as determined by linear regressions (Fig. 3A, D). Evenness and Simpson's index only weakly related to productivity, though the correlation in both cases was significant (Fig. 3B, C). Plant community composition, represented as NMDS1 and NMDS2, correlated significantly with productivity (Fig. 3E, F). According to multiple stepwise regressions, edaphic variables were good predictors for plant diversity and community composition. Forty-three percent of the variance of the Shannon-Wiener value was explained by the edaphic parameters soill and soil4. A $63.2 \%$ of the total variability of richness was explained by soil1-soil4. The combinations of the PCA-derived variables soil $1+$ soil 3 and soil $1+$ soil 2 explained, respectively, $82.1 \%$ and $51.7 \%$ of the variance of NMDS1 and NMDS2 (Table 4). However, only $21.4 \%$ of productivity variation was explained by soill. Edaphic variables were weak predictors of the variation of productivity.

\section{Discussion}

The data and analysis in this study indicate that both biodiversity and community composition are effective measures of productivity in semiarid grasslands, consistent with the results of previous experimental studies (Tilman et al. 2002). Biodiversity measures, such as the Shannon-Wiener index and species richness had positive effects on productivity. Complex measures, such as community composition (NMDS1 and NMDS2), also correlated significantly with productivity. Compared with edaphic factors, both biodiversity and community composition were better predictors of productivity. Abiotic impacts, such as soil nutrition, did not exert as strong an influence as expected (Gough et al. 1994; Schmid 2002).

The relationship between biodiversity and productivity has been described as an asymptotic increase in productivity with an increasing number of species (Naeem et al. 1996; Tilman 1996; Tilman et al. 1997a; Hector et al. 1999; Hooper et al. 2002). The observed patterns in previous studies were largely attributed to sampling effect and niche complementarity. One way to explain these findings is using the sampling effect model that states that dominant species with relatively high productivity play a vital role in the relationship between biodiversity and productivity. In these models, the functioning of highly diverse ecosystems is determined by the traits of whatever species become dominant. A more diverse ecosystem would be more productive because of the greater probability that it contained a highly productive species (Aarssen 1997; Huston 1997). These more productive species can use available resources more efficiently than other species, allowing them to outcompete other species. In this way, species diversity affects productivity because of differences in how efficiently different species use available resources. As a result, both diversity and community composition may affect productivity to the same extent. Another way to explain these findings is using the niche complementarity model, which states that more diverse ecosystems are more likely to contain species that use resources more efficiently, and are therefore more likely to show higher productivity. Sampling effect model predicts that high productivity in highly diverse plots is caused by the presence and dominance of the species that are the most productive in monoculture. In 
Table 2. Average importance value and correlation coefficients of those plant species from the 23 sites that can explain $>50 \%$ of the variance of the nonmetric multidimensional scaling (NMDS) axes, $>40 \%$ of the variance of plant diversity, and $>30 \%$ of the variance of productivity in linear regressions. + and - indicate the direction of the relationship

\begin{tabular}{|c|c|c|c|c|c|c|}
\hline & $\begin{array}{l}\text { Importance } \\
\text { value } \\
\text { (average for } \\
23 \text { plots) }\end{array}$ & $\begin{array}{c}\text { Shannon- } \\
\text { Wiener } \\
\text { value }\left(R^{2}\right)\end{array}$ & $\begin{array}{c}\text { Richness } \\
\quad\left(R^{2}\right)\end{array}$ & $\begin{array}{c}\text { NMDS1 } \\
\left(R^{2}\right)\end{array}$ & $\begin{array}{c}\text { NMDS2 } \\
\left(R^{2}\right)\end{array}$ & $\begin{array}{l}\text { Productivity } \\
\qquad\left(R^{2}\right)\end{array}$ \\
\hline Achnatherum sibiricum & 0.077 & $0.13(+)^{* * *}$ & $0.17(+)^{* * *}$ & - & - & $0.09(-)^{* * *}$ \\
\hline Adenophora gmelinii & 0.036 & - & $0.18(+)^{* * *}$ & - & - & - \\
\hline Allium amsopodium Ledeb & 0.047 & - & - & $0.14(-)^{* * *}$ & - & - \\
\hline Allium polyrrhizum Turcz & 0.175 & $0.23(-)^{* * *}$ & - & $0.17(-)^{* * *}$ & $0.49(-)^{* * *}$ & - \\
\hline Caragana stenophylla & 0.051 & - & - & - & $0.22(-)^{* * *}$ & 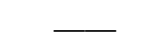 \\
\hline Carex korshinskyi & 0.143 & - & - & - & $0.13(-)^{* * *}$ & - \\
\hline Carex pediformis & 0.099 & - & - & - & $0.22(+)^{* * *}$ & - \\
\hline Chenopodium glaucum & 0.099 & $0.11(-)^{* * *}$ & $0.12(-)^{* * *}$ & $0.37(-)^{* * *}$ & - & $0.11(-)^{* * *}$ \\
\hline Convolvulus chinensis & 0.064 & - & - & $0.17(-)^{* * *}$ & - & - \\
\hline Eragrostis pilosa & 0.065 & - & - & $0.13(-)^{* * *}$ & $0.16(-)^{* * *}$ & 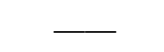 \\
\hline Filifolium sibiricum & 0.046 & - & $0.12(+)^{* * *}$ & - & - & - \\
\hline Iris tigridia & 0.017 & $0.11(+)^{* * *}$ & $0.15(+)^{* * *}$ & - & - & 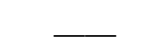 \\
\hline Koeleria cristata & 0.039 & - & - & - & $0.20(+)^{* * *}$ & 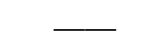 \\
\hline Lespedeza davurica & 0.047 & - & - & - & $0.12(+)^{* * *}$ & - \\
\hline Leymus chinensis & 0.165 & - & - & $0.23(+)^{* * *}$ & - & 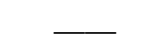 \\
\hline Potentilla tanacetifolia & 0.027 & - & - & - & $0.11(+)^{* * *}$ & 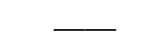 \\
\hline Salsola collina & 0.118 & $0.21(-)^{* * *}$ & $0.26(-)^{* * *}$ & $0.41(-)^{* * *}$ & $0.34(-)^{* * *}$ & - \\
\hline Saussurea amara & 0.013 & - & $0.17(+)^{* * *}$ & - & - & 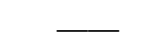 \\
\hline Sibbaldia sericea & 0.062 & 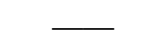 & - & - & $0.17(-)^{* * *}$ & 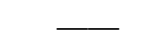 \\
\hline Stipa baicalensis & 0.094 & 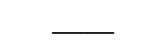 & 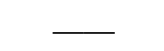 & $0.26(+)^{* * *}$ & $0.18(+)^{* * *}$ & $\longrightarrow$ \\
\hline Stipa krylovii & 0.087 & - & 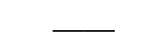 & - & $0.11(-)^{* * *}$ & - \\
\hline Thalictrum minus & 0.030 & $0.25(+)^{* * *}$ & - & - & $0.18(+)^{* * *}$ & $0.10(+)^{* * *}$ \\
\hline Vicia cracca & 0.032 & - & $0.21(+)^{* * *}$ & - & - & - \\
\hline
\end{tabular}

${ }^{* * *} P<0.001$.

contrast, niche complementarity model predicts that the high productivity of highly diverse plots is due to the coexistence and facilitation among species and the traits of particular species compositions. Thus, species number and community composition should be important codeterminants of productivity (Tilman et al. 2002). Both sampling effect models and niche models predict that species diversity matters because species differ in their traits, making species composition as important a determinant of productivity as species diversity (Aarssen 1997; Huston 1997; Tilman et al. 1997b; Tilman 1999).
Functional diversity and functional group composition are widely accepted as effective measures of productivity (Tilman et al. 1997a; Hooper et al. 2002; Naeem and Wright 2003; Reich et al. 2004). Different functional groups and compositions with diverse traits are expected to have different effects on productivity. For instance, Tilman arranged several available combinations of functional groups in Cedar Creek, Minnesota, USA, and measured how biodiversity (e.g., through species richness), the number of functional groups, and the composition of functional groups affect productivity. The results indicate that in addition to species richness, 
Table 3. Eigenvalues and eigenvector coefficients of standardized principal component analysis (PCA)

\begin{tabular}{lrrrr}
\hline PCA & Axis1 & Axis2 & Axis3 & Axis4 \\
\hline & Soil1 & \multicolumn{1}{c}{ Soil2 } & \multicolumn{1}{c}{ Soil3 } & \multicolumn{1}{c}{ Soil4 } \\
Eigenvalue & 5.51 & 1.96 & 1.09 & 0.57 \\
Cum.\% of var & 55.10 & 74.66 & 85.57 & 91.25 \\
SOC & -0.40 & 0.12 & 0.18 & 0.17 \\
TP & -0.14 & 0.65 & -0.05 & 0.34 \\
AP & 0.09 & 0.45 & 0.50 & -0.70 \\
TN & -0.38 & 0.23 & -0.10 & 0.03 \\
AN & -0.31 & 0.02 & -0.39 & -0.14 \\
C/N & -0.29 & -0.08 & 0.60 & 0.36 \\
C/P & -0.36 & -0.31 & 0.31 & 0.00 \\
N/P & -0.31 & -0.43 & -0.03 & -0.30 \\
SWC & -0.38 & 0.05 & -0.11 & -0.33 \\
BD & 0.35 & -0.17 & 0.29 & 0.08 \\
\hline
\end{tabular}

both the number of functional groups and the composition of functional groups had effects on productivity. However, functional group composition is better than the number of functional groups as a predictor of productivity (Tilman et al. 1997a). One of the primary challenges of measuring community composition is how to determine appropriate methods to define functional diversity. Wright et al. (2006) have pointed out that the method for classifying functional groups widely used in current studies, which relies on a grass/forb/legume scheme, underestimates the effect of functional diversity on productivity. This is because the method is not sufficiently efficient or precise to capture all the traits affecting functional diversity. In order to detect the primary aspects of biodiversity affecting productivity and avoid distorting the effects of community composition on productivity, we tested the regression of community composition and productivity using a distance-measuring method called NMDS. This approach allowed us to measure effectively the variance and covariance difference within and among plant communities, and other investigations have found NMDS to be effective in their studies (Kahmen et al. 2005).

Our results indicate that community composition is a good predictor of productivity. The parameters derived from community composition (NMDS1 and NMDS2) had significant positive effects on productivity (Fig. 3E, F). Kahmen et al. reported a similar result concerning the effect of community composition on productivity in European montane grasslands. Their results showed community composition to be a better predictor of productivity than species richness. In contrast to our results, however, they did not find a significant effect of species richness on productivity, possibly because the high number of plant species in natural ecosystems, such as that examined here exceeds that in the low-diversity plots in American and European experiments. Other possible factors that may explain the differences between our results and those of Kahmen et al. are the different land-use patterns and land-use history, which can affect the relationship between biodiversity and productivity (Osem et al. 2002; Zhou et al. 2006). The minimum species richness in our natural grassland ecosystem was six and our 3-year observations indicate that species richness above five has significant effects on productivity. Therefore, inadequate species richness does not explain the weak relationship that we observed here between this parameter and productivity.

The effect of biodiversity on productivity observed in this study is similar to the results of previous experimental researches (Tilman 1996; Hector et al. 1999; Troumbis and Memtsas 2000). Our work found biodiversity and productivity to have a positive relationship: plots with higher biodiversity, as measured by the Shannon-Wiener index and species richness, show higher productivity (Fig. 3A, D). Ecosystem functioning has been reported to depend on both the identities (community composition) and the numbers (species richness) of its species (Tilman et al. 1997b). Natural ecosystems are composed of species with different traits, which show higher or lower productive ability in monoculture. Different traits among plant species cause the variance in ecosystem functioning. Therefore, it is difficult but necessary to distinguish between species richness and plant community composition in observational research. As predicted by the sampling effect and niche complementarity models, our results show that an increase in the number of species changes the species diversity and composition of an ecosystem. Productivity increases with species richness and is positively affected by community composition (Fig. 3), meaning that an ecosystem with a smaller number of species would have lower 

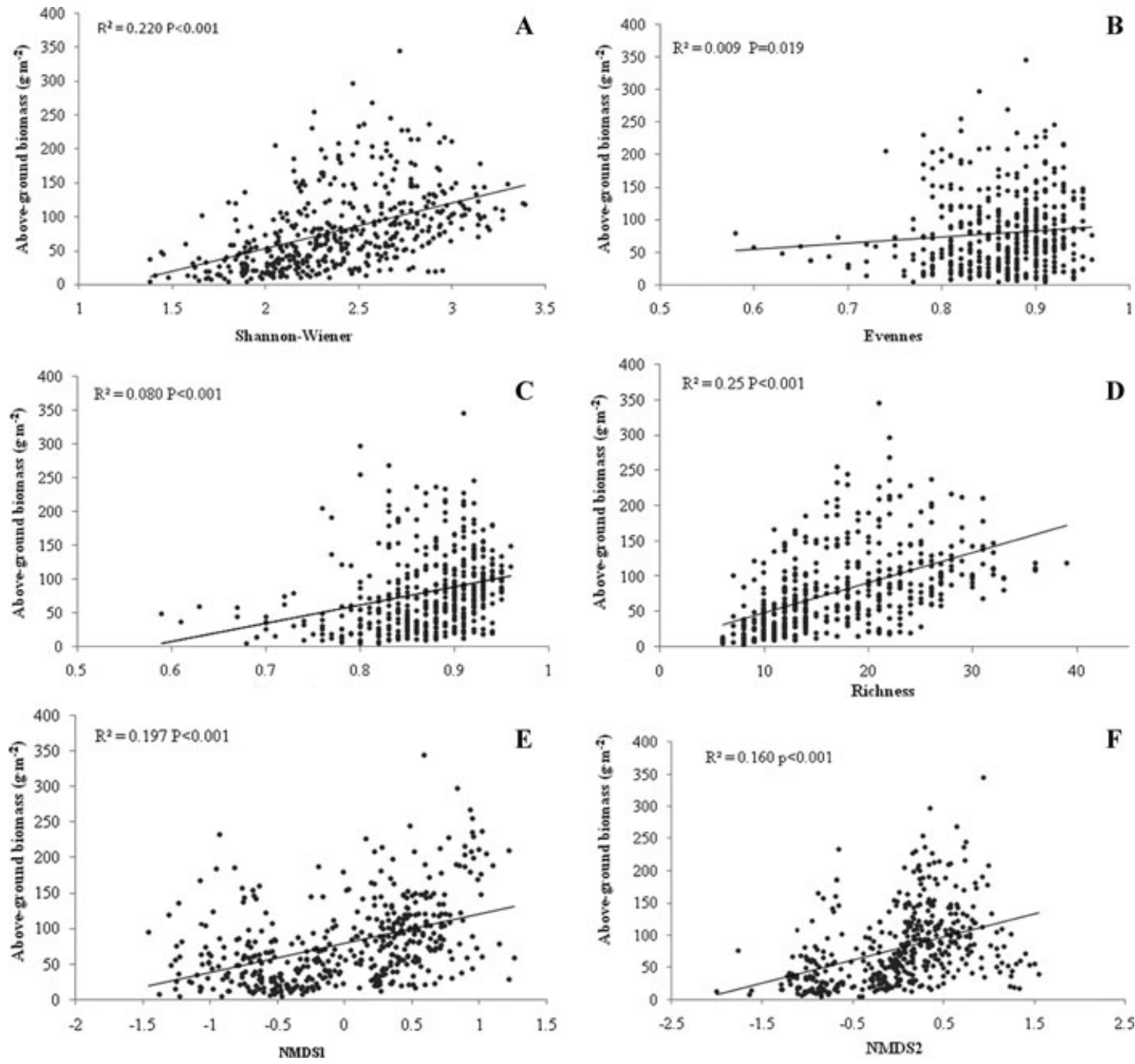

Figure 3. Relationship among biodiversity, plant community composition, and productivity. (A) The relationship between aboveground biomass and Shannon-Wiener value. (B) The relationship between aboveground biomass and evenness. (C) The relationship between aboveground biomass and Simpson's index. (D) The relationship between aboveground biomass and species richness. (E) and (F) show the relationship between aboveground biomass and community composition parameters NMDS1 and NMDS2, respectively.

productivity than one containing a higher number of species.

In natural ecosystems, environmental factors, such as edaphic parameters can greatly influence the relationship between biodiversity and ecosystem functioning. In addition, the overwhelming effects of abiotic variables should not be ignored (Loreau et al. 2001). For example, small differences in soil conditions can have a large effect on plant growth and species diversity and thus affect ecosys- tem functioning (Huston and McBride 2002). Interestingly, the results in our study (Fig. 3A, D) support the notion that plant species richness is maximal at intermediate levels of productivity in several different natural grassland ecosystems (Waide et al. 1999; Mittelbach et al. 2001; Schmid 2002). This finding may be explained by the theory introduced by Schmid, because the soil condition in our study sites is also heterogeneous. Schmid combined the hump-shaped relationship derived from 
Table 4. Multiple stepwise regression models of plant diversity (Shannon-Wiener, species richness), community composition (NMDS1 and NMDS2), and productivity

\begin{tabular}{|c|c|c|c|c|c|c|}
\hline \multirow[b]{2}{*}{ Dependent variable } & \multicolumn{4}{|c|}{ Details of multiple regression model } & \multicolumn{2}{|c|}{ Model summary } \\
\hline & Variable & $B$ & $P$ & $R^{2}$ & $R^{2}$ & $P$ \\
\hline \multirow[t]{2}{*}{ Shannon-Wiener } & Soill & -0.091 & $<0.001$ & 0.383 & 0.430 & $<0.001$ \\
\hline & Soil4 & -0.099 & 0.022 & 0.046 & & \\
\hline \multirow[t]{4}{*}{ Richness } & Soil1 & -1.810 & $<0.001$ & 0.513 & 0.632 & $<0.001$ \\
\hline & Soil2 & -1.750 & 0.005 & 0.003 & & \\
\hline & Soil3 & -0.180 & 0.008 & 0.043 & & \\
\hline & Soil4 & -0.700 & 0.035 & 0.049 & & \\
\hline \multirow[t]{2}{*}{ NMDS1 } & Soill & -0.210 & $<0.001$ & 0.810 & 0.821 & $<0.001$ \\
\hline & Soil3 & -0.056 & 0.044 & 0.011 & & \\
\hline \multirow[t]{2}{*}{ NMDS2 } & Soil1 & -0.103 & $<0.001$ & 0.207 & 0.517 & $<0.001$ \\
\hline & Soil2 & -0.212 & $<0.001$ & 0.310 & & \\
\hline Productivity & Soil1 & -7.617 & $<0.001$ & 0.213 & 0.214 & $<0.001$ \\
\hline
\end{tabular}

observational biodiversity studies with the results from experimental studies that showed that high biodiversity caused increasing productivity. He concluded that soil fertility is an important factor affecting the relationship between biodiversity and productivity, since changes in soil fertility can influence the level of biodiversity and productivity (Schmid 2002). In this study, the results of stepwise regression performed comparing PCA parameters derived from edaphic variables with biodiversity, NMDS parameters and productivity showed that only Soill correlated with productivity. In contrast, soill and soil4 had significant effects on the Shannon-Wiener index; soill-soil4, on species richness; soil1 and soil3, on NMDS1; and soil1 and soil2, on NMDS2. Soil1 was related to SOC, TN, SWC, and $\mathrm{BD}$, all of which were basic soil nutrition and soil physical traits. Parameters reflecting available soil fertility, including AN and AP, were related to soil3 and soil4. This available nutrition could have readily leached out of the ecosystem, and the resulting loss of these nutrients would have had significant effects on nutrient retention (Tilman et al. 1997b). The coefficient in the model examining PCA parameters and productivity was markedly smaller than in the models of PCA parameters involving biodiversity and community composition. In addition, the results of Pearson's correlation showed that a significant covariation of PCA1 with productivity $\left(R^{2}=0.21, P<0.01\right)$ was much weaker than it was with richness $\left(R^{2}=0.50, P<0.01\right)$ and NMDS1 $\left(R^{2}=0.81, P<0.01\right)$. Therefore, the edaphic variables showed a stronger relationship with biodiversity and community composition than with productivity and they were better at predicting these biotic variables than predicting productivity. The impact of soil differences on productivity may affect biodiversity and community composition indirectly.

Dominant species with high productivity form the foundation of sampling effect models. Special functional group plants, such as $\mathrm{C} 4$ and legume plants, contribute vastly to productivity and thereby affect the relationship between biodiversity and ecosystem functioning (Tilman et al. 1997a; Spehn et al. 2002). Some rare or less-common species are also thought to affect biodiversity and community composition (Lyons et al. 2005). Our results from linear regression between plant data and biodiversity, which significantly affect productivity, NMDS1, and NMDS2, show that few species have significant effects on productivity. However, several species had significantly positive or negative effects on biodiversity, NMDS1, and NMDS2 (Table 2). Of the three species that correlated with productivity, two (Achnatherum sibiricum, Chenopodium glaucum) are $\mathrm{C} 4$ plants. This result is consistent with the conclusions of several previous studies (Tilman et al. 1997a). Nevertheless, more species in our sampling sites correlated with biodiversity and community composition. Some of these species were 
dominant species, such as Allium polyrrhizum Turcz, Salsola collina, Leymus chinensis, and Stipa baicalensis whose relative importance value was more than or approximately 0.1 . Some rare or less-common species, such as Vicia cracca, Thalictrum minus, and Caragana stenophylla had a stronger relationship with biodiversity or with NMDS1 and NMDS2 than did dominant species (Table 2). Their relative importance values were approximately or less than 0.05 . These findings indicate that dominant species and some rare or less-common species can significantly affect biodiversity and community composition.

Although it was difficult to detect an "overyielding" effect in natural ecosystems, we attempted to elucidate how biodiversity and ecosystem functioning are related. Our results suggest that niche complementarity models are superior to sampling effect models for explaining the relationship between community composition and productivity in our ecosystem. First, it was not a single dominant, productive species but rather a combination of plant species (including several dominant and rare species) that had significant effects on productivity through indirect interactions between biodiversity and community composition. Second, the results of Pearson's correlation indicated that the coefficient of productivity with richness $\left(R^{2}=0.50\right.$, $P<0.01)$ was greater than it was with NMDS1 $\left(R^{2}=0.25, P<0.01\right)$ or NMDS2 $\left(R^{2}=0.32\right.$, $P<0.01)$. The variance of productivity was caused mainly by species richness, consistent with the results of Tilman's analytical model (Tilman et al. 1997b).

The mechanisms underlying the relationship between biodiversity and ecosystem functioning are complicated. Indeed, many factors coexist in natural grassland ecosystems. The variations in ecosystem functioning (such as ecosystem productivity) will depend largely on which driver-whether biotic or abiotic-dominates at a given point in time. Further study should seek to develop observational and analytical methods to control and separate environmental parameters and discuss the underlying mechanisms. In ecosystem management, simple species numbers should be considered in conjunction with plant community composition, because simple increases in species number will not necessarily improve ecosystem functioning. Furthermore, the impact of not only dominant species but also that of some rare or less-common species should be taken into account in studies dealing with biodiversity conservation. Indeed, the effects of rare species on ecosystem functioning were not discussed in this study and they demand further investigation.

According to the results of this study, we conclude that both biodiversity and plant community composition affect productivity. Furthermore, environmental parameters, such as soil conditions, have more significant effect on predicting biodiversity and community composition than on productivity. In addition, abiotic factors, such as soil nutrition conditions, may affect productivity indirectly by affecting biotic factors, such as species biodiversity and plant community composition. Finally, the relationship between biodiversity and productivity in this study is better explained by niche complementarity models than by sampling effect models.

\section{Acknowledgments}

This study was financially supported by the $\mathrm{Na}$ tional Basic Research Program of China (No. 2009CB421104) and the National Natural Science Foundation of China (No. 40621061). We are grateful to Yugang Zhang, Jiaming Zhao, Zhitao Meng, Ruidong Wang, Kui Li, Xiaoyu Bai, and Li Chen from the Institute of Environmental Science of Inner Mongolia for their assistance in the field investigation.

\section{Conflicts of interest}

The authors declare no conflicts of interest.

\section{References}

Aarssen, L.W. 1997. High productivity in grassland ecosystems: affected by species diversity or productive species? Oikos 80: 183-184.

Cardinale, B.J., K. Nelson \& M.A. Palmer. 2000. Linking species diversity to the functioning of ecosystems: on the importance of environmental context. Oikos 91: 175183.

Chapin, F. S., E.S. Zavaleta, V.T. Eviner, et al. 2000. Consequences of changing biodiversity. Nature 405: 234-242.

Chen, X., X.S. Zhang \& B.L. Li. 2003. The possible response of life zones in China under global climate change. Global Planet. Change 38: 327-337.

Clarke, K.R. 1993. Non-parametric multivariate analyses of changes in community structure. Austral Ecol. 18: 117143. 
Diaz, S. \& M. Cabido. 2001. Vive la difference: plant functional diversity matters to ecosystem process. Trends Ecol. Evol. 18: 140-146.

Faith, D.P., P.R. Minchin \& L. Belbin. 1987. Compositional dissimilarity as a robust measure of ecological distance. Vegetatio 69: 646-655.

Gough, L., J.B. Grace \& K.L Taylor. 1994. The relationship between species richness and community biomass: the importance of environmental variables. Oikos 70: 271279.

Grime, J.P. 1997. Biodiversity and ecosystem function: the debate deepens. Science 277: 1260-1261.

Hector, A., B. Schmid, C. Beierkuhnlein, et al. 1999. Plant diversity and productivity experiments in European grasslands. Science 286: 1123-1127.

Hooper, D.U. \& P.M. Vitousek. 1997. The effects of plant composition and diversity on ecosystem processes. Science 277: 1302-1305.

Hooper, D.U., M. Solan, A. Symstad, et al. 2002. Species Diversity, Functional Diversity, and Ecosystem Functioning. Oxford University Press. New York, NY.

Huston, M.A. 1997. Hidden treatments in ecological experiments: re-evaluating the ecosystem function of biodiversity. Oecologia 110: 449-460.

Huston, M. A. \& A.C. McBride. 2002. Evaluating the Relative Strengths of Biotic Versus Abiotic Controls on Ecosystem Processes. Oxford University Press. New York, NY.

Huston, M.A., L.W. Aarssen, M.P. Austin, et al. 2000. No consistent effect of plant diversity on productivity. Science 289: 1255 a.

Inner Mongolia Fedral Investigation Team of CAS. 1985. Inner Mongolia Vegetation. Science Press. Beijing.

Kahmen, A., J. Perner \& N. Buchmann. 2005a. Diversitydependent productivity in semi-natural grasslands following climate perturbations. Oikos 19: 594-601.

Kahmen, A., J. Perner, V. Audorff, et al. 2005b. Effects of plant diversity, community composition and environmental parameters on productivity in montane European grasslands. Oecologia 142: 606-615.

Lavorel, S. \& E. Garnier. 2002. Predicting changes in community composition and ecosystem functioning from plant traits: revisiting the Holy Grail. Func. Ecol 16: 545-556.

Li, B.L. \& E.L. Charnov. 2001. Diversity-stability relationships revisited: scaling rules for biological communities near equilibrium. Ecolog. Modell. 140: 247-254.

Loreau, M. \& A. Hector. 2001. Partitioning selection and complementarity in biodiversity experiments. Nature 412: 72-76.

Loreau, M. 1998. Separating sampling and other effects in biodiversity experiments. Oikos 82: 600-602.
Loreau, M. 2000. Biodiversity and ecosystem functioning: recent theoretical advances. Oikos 91: 3-17.

Loreau, M., S. Naeem, P. Inchausti, et al. 2001. Biodiversity and ecosystem functioning: current knowledge and future challenges. Science 294: 804-808.

Lu, R. 1999. Analytical Methods of Soil Agrochemistry. Chinese Agriculture Science and Technology Press. Beijing.

Lyons, K.G., C.A. Brigham, B.H. Traut \& M.W. Schwartz. 2005. Rare species and ecosystem functioning. Cons. Bio. 19: 1019-1024.

Mittelbach, G.G., C.F. Steiner, S.M. Scheiner, et al. 2001. What is the observed relationship between species richness and productivity? Ecology 82: 2381-2396.

Naeem, S. \& J.P. Wright. 2003. Disentangling biodiversity effects on ecosystem functioning: deriving solutions to a seemingly insurmountable problem. Ecol. Lett. 6: 567579.

Naeem, S., L.J. Thompson, S.P. Lawler, et al. 1994. Declining biodiversity can alter the performance of ecosystems. Nature 368: 734-737.

Naeem, S., K. Hakansson, J.H. Lawton, et al. 1996. Biodiversity and plant productivity in a model assemblage of plant species. Oikos 76: 259-264.

Osem, Y., A. Perevolotsky \& J. Kigel. 2002. Grazing effect on diversity of annual plant communities in a semiarid rangeland: interactions with small-scale spatial and temporal variation in primary productivity. J. Ecol. 90: 936-946.

Petchey, O.L. \& K.J. Gaston. 2002. Functional diversity (FD), species richness and community composition. Ecol. Lett. 5: 402-411.

Reich, P.B., D. Tilman, S. Naeem, et al. 2004. Species and functional group diversity independently influence biomass accumulation and its response to $\mathrm{CO}_{2}$ and N. Proc. Natl. Acad. Sci. 101: 10101-10106.

Schmid, B. 2002. The species richness-productivity controversy. Trends Ecol. Evol. 17: 113-114.

Spehn, E.M., M. Scherer-Lorenzen, B. Schmid, et al. 2002. The role of legumes as a component of biodiversity in a cross-European study of grassland biomass nitrogen. Oikos 98: 205-218.

Thompson, K., A.P. Askew, J.P. Grime, et al. 2005. Biodiversity, ecosystem function and plant traits in mature and immature plant communities. Func. Ecol. 19: 355-358.

Tilman, D. 1996. Productivity and sustainability influenced by biodiversity in grassland ecosystems. Nature 379: 718-720.

Tilman, D. 1999. The ecological consequences of changes in biodiversity: a search for general principles. Ecology 78: 81-92. 
Tilman, D., J. Knops, D. Wedin, et al. 1997a. The influence of functional diversity and composition on ecosystem processes. Science 277: 1300-1302.

Tilman, D., C.L. Lehman \& K.T. Thomson. 1997b. Plant diversity and ecosystem Productivity: Theoretical considerations. Proc. Natl. Acad. Sci. 94: 18571861.

Tilman, D., P.B. Reich, J. Knops, et al. 2001. Diversity and productivity in a long-term grassland experiment. Science 294: 843-845.

Tilman, D., J. Knops, D. Wedin \& P.B. Reich. 2002. Plant Diversity and Composition Effects on Productivity and Nutrient Dynamics of Experimental Grasslands. Oxford University Press. New York, NY.

Troumbis, A.Y. \& D. Memtsas. 2000. Observational evidence that diversity may increase productivity in Mediterranean shrublands. Oecologia 125: 101-108.

Waide, R.B., M.R. Willig, C.F. Steiner, et al. 1999. The relationship between productivity and species richness. Ann. Rev. Ecol. Systemat. 30: 257-300.

Wright, J.P., S. Naeem, A. Hector, et al. 2006. Conventional functional classification schemes underestimate the relationship with ecosystem functioning. Ecol. Lett. 9: 111120.

Zhang, Q.G. \& D.Y. Zhang. 2006. Species richness destabilizes ecosystem functioning in experimental aquatic microcosms. Oikos 112: 218-226.

Zhou, Z., O.J. Sun, J. Huang, et al. 2006. Land use affects the relationship between species diversity and productivity at the local scale in a semi-arid steppe ecosystem. Functl. Ecol. 20: 753-762. 